\title{
NEgotiating THE NATURE OF MYSTICAL EXPERIENCE, GUIDED BY JAMES AND TILLICH
}

\author{
DAVID NIKKEL
}

THIS ARTICLE ORIGINALLY APPEARED IN THE BULLETIN OF THE NORTH AMERICAN PAUL TILLICH SOCIETY, SUM 2007.

Informed by William James's and Paul Tillich's respective understandings of mystical experiences, this essay will venture into contemporary epistemological debates on the nature of mystical experience. Over the past fourteen years of that debate, no less than seven articles focusing on mystical experience have marked the pages of the Journal of the American Academy of Religion, the most widely circulated religious studies periodical. In its critical-constructive work, this paper will ultimately offer an embodied model of such experience that attempts to mediate between two polar positions.

Let me begin with a summary of the debate between those diametrically opposed construals, between essentialists and cultural-religious constructivists, the former maintaining a common, even sui generis, basis for mystical experience involving intimate contact with the divine. I will divide the essentialists into two camps: (1) those like W. T. Stace, Robert K. C. Forman, and Jonathan Shear who claim that some experiences are of immediate identity, undifferentiated unity, transcending completely the subject-object structure; (2) others, like Bernard McGinn, Moshe Idel, and Henry Simoni-Wastila, who counter that any mystical experience must have some object not identical with the mystical subject without remainder. This latter implies some mediation, though much of the normal mediation inherent in human consciousness may drop away.

In their portrayals of immediate identity, Stace, Forman, and Shear emphasize the purity of mystical experience, that is, its contentless nature. It is an experience of nothing-no-thing-in particular, non-intentional in the sense of intending no object. Forman labels it a "pure consciousness event (PCE)" and Shear an "introspective mystical experience (IME)." Shear goes on to describe it "as devoid of phenomenological contents (sense perceptions, images, thoughts, emotions, sense of individual identity, etc.) whatsoever" (320). Earlier Stace wrote of "a kind of consciousness which has no objects," "without any empirical content" (82). Unlike these three thinkers, I would raise the possibility of our ordinary, everyday consciousness occasionally lacking focus on any particular object, thought, emotion, etc. Clearly, however, these essentialists intend something extraordinary about the nature of mystical experience. In his Journal of the American Academy of Religion piece, Forman does not commit himself to any one interpretation of awareness per se, of the "knowledge by identity," of mystical experience: the fact that "it is beyond all ordinary concepts and language, leaves it open to a virtually infinite range of theories, explanations, modes of expressions and descriptions" (727). However, the mystics he cites consistently interpret this experience as one co-extensive with the ultimate reality behind all things. Following Stace, Shear sanctions bypassing the need for interpretation by positing an "extrovertive mystical experience (EME)" related to the introvertive, delineated as "awareness of this same empirically contentless, abstract, transcendental 'reality' as underlying every object in one’s experience, external (trees, the sky, etc.) as well as internal (thoughts, feelings, etc.)” (320).

Unlike the proponents of undifferentiated unity, the other camp of essentialists stresses the metaphysical particularity and distinctness of finite human beings. Simoni-Wastila puts it this way: "Human beings, who by nature are finite and limited in their metaphysical boundaries, can never escape their particular natures. They cannot join with or become undifferentiated from God's creative oneness, unity, and simplicity” (858). 
Thus, Simoni-Wastila, along with McGinn and Idel, maintain some necessary distinction between subject and object in mystical experience. In so doing, they stand with most modern philosophy since Hume and Kant in insisting that consciousness is always intentional, always of something. I note here that James's model of perception of a wider consciousness normally subliminal to our consciousness falls under the category of mystical experience as involving an object rather than that of undifferentiated unity.

Before leaving this discussion of the essentialists, allow me to complicate things further by introducing additional distinctions. Clearly the first camp posits an undifferentiated experience of identity of human and divine beyond the subject-object structure. Nevertheless, proponents of such experience typically do not hold that this experience encompasses all of God's or the divine consciousness. Divine knowledge of the world represents a prime example of contents of consciousness that mystics typically do not claim. (Interestingly, Simoni-Wastila demurs from divine omniscience to ensure the "radical particularity" of creatures, contending that "God cannot know our heart of hearts" (860). While process theology strenuously rejects his opinion that "God cannot fully co-experience the feelings of others" (861), it does delay God's all-inclusive knowledge of a creature's experience till after the unit occasion has made its decision, lest God pantheistically determine that decision.) In a move towards monism, one way to handle this possible discrepancy, as in neo-Platonism and Advaita Hinduism, relegates divine knowledge of the world to lower knowledge. Nous (Greek, "mind”) knows the Platonic forms and the World Soul the material world, while Saguna Brahman comprehends the world according to Advaita Hinduism. The One of Plotinus or Advaita's Nirguna Brahman remain unsullied by lower knowledge, experiencing only the higher knowledge of pure oneness, an experience the mystic believes she or he shares. While the devotee of unmediated identity traditionally holds that knowledge of the world drops away in mystical experience, another option is theoretically possible: Just as the divine in the opinion of some has both the knowledge of pure oneness and of the world, one could maintain that the mystic at one and the same time has knowledge of undifferentiated unity with the divine at the highest level along with some ordinary consciousness of its being in the world.

In fact, that is precisely Paul Tillich's position. Therefore, Tillich's thought has affinities with the camp of undifferentiated unity over against those who uphold some subject-object distinction. Tillich insists on that point of "identity" in all religious experience in his "doctrine" of the "mystical a priori" (23), whether that experience be a cultivated mystical state of substantial duration or not. On the other hand, Tillich's posited experience of that which precedes the subject-object cleavage never constitutes the whole field of any moment of human awareness. Furthermore, a mediation of sorts always pertains: in this life at least one never has an experience of unity beyond subject-object without something within the subject-object structure of the world becoming the vehicle or springboard for the experience. As I have argued elsewhere, visual art provided that springboard for Tillich personally (Nikkel, 2006b: 17-21). The raft metaphor from some forms of Eastern spirituality may help here: while the raft or object is necessary to get to the other side, one throws it away because it becomes irrelevant there. Because of the incidental nature of the specific content of the finite that occasions mystical identity and because it is distinct from the experience of identity, this experience maintains its "purity."

On the opposite side are constructivists like Steven Katz, Hans Penner, and Wayne Proudfoot, who maintain that no common core exists in mystical experiences, whether mediated or beyond all mediation. Rather, mystical experiences are wholly constructed by the mystic out of his or her own religious tradition. Note that the second group of essentialists above allows for some construction of the experience by the mystic, though crucially insisting on objective contact with the divine. One could label them as not simply essentialists but contextualists as well. "Constructivism," as I refer to it, is thoroughgoing. Its assumption is both that there is no 
objective religious object that is mediated and that the strictly subjective constructions are unique to each mystic. Thus, either no mediated object internal to the mind obtains or, in the case of Proudfoot, an inchoate emotive-physiological state receives linguistic definition (see G. William Barnard on Proudfoot).

Judging that the above brief overview will suffice for introducing the relatively clear-cut constructivist position, I will broach an additional option before critiquing constructivism. Simoni-Wastila, Martin T. Adam, and F. Samuel Brainard have recognized various efforts to find a third way to "mediate" the gap between essentialists and constructivists. Brainard notes the strategy of some, like Michael Sells on Western mysticism and Toshihiko Izutsu on Eastern mysticism, to acknowledge the similarity of mystical texts while bracketing the "ultimate" question of a common core (361-62). However, such skimming of the surface, so to speak, merely postpones rather than dissolves the question of a common core. Brainard favors a tertium quid of his own centering on the paradox of certain language about ecstatic experiences that both retains and collapses the subject-object scheme (385ff). Brainard's proposed solution entails embracing the validity of "both-and" mystical experiences, where supposedly the subject-object/ nominalist-realist/ constructivist-essentialist distinctions are both upheld and transcended at the same time. Looming in the background is the ineffability of mystical experience, as Brainard assumes that language cannot get beyond an either-or answer to the question of these polarities. Though he does not find them promising, Brainard also mentions "no-pole (e.g., nonfoundational...) alternatives" (388). He includes "perhaps James's pragmatism” here but says no more. Maybe Brainard alludes to James's theory of pure experience where subject-object are blended at the most fundamental level. This theory might dissolve the paradox of mystical experience through its analogy to (a basic level) of ordinary experience. Yet this model of perception does involve contents and ultimately (further or greater) objectification. Or perhaps Brainard simply alludes to James's belief that moral fruitfulness constitutes one test of a mystical experience's validity. James, however, has much more to say on the matter and believes overall in the objective truth of mystical experience. Finally Brainard mentions (388) and Adam describes a "family resemblance" approach: "mak[ing] no ontological claims... It acknowledges family resemblances among the diversity of experiences called 'mystical' while at the same time picking out for examination subsets of experiences having similar descriptions" (813). As with the approach of noting textual similarities, though, this approach just postpones or ignores the ultimate issue: Are mystical experiences just constructed from traditions by individuals or is there a common core-or perhaps several common cores-behind them?

Brainard's proffered solution represents the most interesting of these various middle ways, so I will address it separately. Its plausibility rests on the truth that any experience with nonlinguistic elements can never be fully expressed through language—so how much more might that be the case with an ultimate experience of ultimate reality.

Yet, if we can bother to verbalize about mystical experience at all, I would insist that we could say something about the manner and the extent to which it transcends or blurs and to which it retains the subject-object distinction. The fact that mystics' own linguistic interpretations of their experiences disagree on whether and to what extent this distinction remains, while belying any easy consensus on the matter, at least supports the possibility of saying something relevant. Likewise, I would insist that we can say something about whether mystical experiences are wholly constructed by the subject or have some "objective" reality behind them. Brainard agrees with what James labeled the "noetic" quality of mystical experience, that the mystic believes he or she is in touch with some reality. But Brainard's apparent contentment with leaving it there, declining to verbalize about the nature of that reality, strikes me as a cop-out. A constructivist would certainly feel no challenge to take mystical experiences seriously on those terms—or lack thereof. 
The fundamental weakness of these above attempts at a tertium quid is this: they do not help to resolve the debate unless and until they address what, if anything, is mediated-or unmediated-in mystical experience. This brings us back to the question of a common core. Common sense seems to cry out for some common or similar core(s) to mystical experiences. Very similar descriptions of experiences of pure consciousness beyond subject-object cut across various traditions, as do depictions of mystical experiences of divine love. Furthermore, beyond anecdotal evidence of the physiology and mental functioning of meditative adepts, earlier scientific studies monitored the autonomic nervous system (through pulse and blood pressure measurements) and brain wave patterns (using electroencephalography [EEG]) during meditation while contemporary scholars like Eugene d'Aquili and Andrew Newberg have imaged neurological patterns in brain activity common to mystical states.

Let me summarize the scientific findings thus far. At least four brain areas appear relevant to mystical experiences: the thalamus (involved in integrative and non-specific functions), the limbic system (involved with emotions), parts of the pre-frontal cortex, and the posterior sections of the parietal lobes. These latter two areas have the most prominent roles in mystical experiences. The posterior parietal lobes house what Newberg terms "the Orientation Association Area (OAA)” (2002). More specifically the left lobe provides a spatial sense of self, while the right defines the physical space in which the self interacts. The pre-frontal cortex contains "the Attention Association Area (AAA)," which focuses attention on intentional or goal-directed thought, actions, and behavior (Newberg, 2002). In particular, parts of the pre-frontal cortex show elevated activity during thinking about or acting on social relationships (Monastersky). How do cognitive neuroscientists learn what happens in the relevant parts of the brain during meditative and other states? Able to expand upon general conclusions from EEG studies, functional magnetic resonance imaging (fMRI) detects blood flow, while positron emission tomography (PET) and single photon emission computed tomography (SPECT) can also monitor metabolism and some neurotransmitter activity.

While other areas of the brain undoubtedly also play a role in our sense of self, as suggested earlier the posterior parietal lobes figure crucially. D'Aquili and Newberg coined the phrase "the Unitary Continuum" to refer to the degree of connectedness to others — or to put it conversely how sharply the self is defined over against others - in various human experiences. On the "less connectedness" side of baseline fall some pathological conditions, including depression. On the extreme of the "more connectedness" side falls what they identify as "Absolute Unitary Being." Newberg describes this state as one "where there is no perception of spatial or temporal boundaries whatsoever, accompanied by the experience of absolute unity, devoid of content and with even the self-other dichotomy obliterated” (2002). D'Aquili and Newberg's familiarity with the model of undifferentiated identity of one essentialist camp is unmistakable. Neurological studies so far have not been so precise as to distinguish definitively between reported experiences of undifferentiated unity versus those of a unity of love versus those of "cosmic consciousness," as Newberg cites the well-known experience of Richard Bucke of the universe as a living consciousness even as individuals retain their individuality (2002). Nevertheless, neuro-studies yield a consensus on reduced activity in the posterior parietal lobes during meditative and contemplative states, pointing to a diminished sense of self vis-à-vis others or, put positively, a greater sense of connectedness and unity with others.

Inversely the studies generally show increased activity in parts of the pre-frontal cortex, apparently corresponding to focusing on relationships with others. In experiences of undifferentiated unity, we seem to find enhanced focus but not on any object in particular. Studies of the autonomic nervous system, as summarized by Newberg, support the existence of this paradoxical condition. Some studies have associated meditation with a relaxed state where the parasympathetic nervous system kicks in and lowers heart and respiratory rates, blood pressure, 
and metabolism - this would be the common wisdom. Other studies have suggested a more complex picture of meditative states: heightened activity of the parasympathetic nervous system can happen at the same time as heightened activity of the sympathetic nervous system, the system associated with arousal (increased variability of heart rate is one sign of this). As Newberg notes, this "fits characteristic descriptions of meditative states in which there is a sense of overwhelming calmness as well as significant alertness" (2006).

When we move from physiological and neurological studies to a purported genetic basis for the sense of spiritual connection, we slide on thinner ice. I share with most other participants in the religion and science dialogue some skepticism about Dean Hamer's assertion of a "God gene." While he does acknowledge the influence of culture and more personal environment on individuals' spirituality, his precise claim that genes account for half of the variations in degree of spirituality strikes me and others as too quantitative and reductive for such a complex dimension of human life. Despite my caveat, Hamer may be on to something regarding human tendencies to construct a sharp sense of self versus tendencies to feel connected to wider realities, which would have obvious implications for mystical experiences. Specifically a variation of the gene VMAT2 in some individuals allows for greater dopamine, serotonin, and noradrenaline effects, apparently on the pre-frontal area associated with relationships with others. This suggests that some persons have a stronger proclivity towards unitive experiences than others. In general, this thesis harmonizes with a 2002 neurological study cited by Newberg, indicating increased dopamine activity "during meditation related practices" (2006). In an interesting negative example, decreased activity in this area seems to be associated with a decreased sense of connection with others: a 1994 study showed decreased glucose metabolism in murderers (Newberg, 2002).

Thus, both common sense and diverse scientific studies point to some common or similar core(s) to mystical experience. Yet the constructivist position, presented by Stephen Katz in his 1978 Mysticism and Philosophical Analysis that launched the current debate, defies such apparent common sense and scientific research. Hans Penner probably has stated these constructivist ramifications most bluntly: "...mysticism now covers a host of beliefs and experiences which have no relation to each other whatsoever." As Martin Adam has aptly observed regarding the Kantian perspective in which Katz understands himself to stand, a peculiarity emerges: for Katz no particular data or object is present in mystical experience to interpret - the concepts of the mystic's tradition are wholly determinative; so everything is interpretation but ironically nothing pushes back on us calling for interpretation. For Kant, noumena-objects in themselves-are never experienced; rather one experiences the appearances of the object, namely, phenomena. For Kant, though, we perforce unconsciously interpret objects through basic categories like space and time. The conscious concepts of religious traditions constitute another layer of interpretation. However, as Adam notes, not only the constructivists but some essentialists as well conflate the two types of interpretation, usually by reducing all interpretation to the more or less conscious conceptual level (804ff.).

Not surprisingly, Katz finds the strongest support for his position of interpretation all the way down in the difference between claimed experiences of undifferentiated unity versus those where some distinction remains between subject and object: There is no intelligible way that anyone can legitimately argue that a "no-self" experience of "empty" calm is the same experience of intense, loving, intimate relationship between two substantial selves, one of whom is conceived as the personal God of western religion and all that this entails (39-40).

Obviously my structuring of this article recognizes the validity and importance of this distinction. However, noting a distinction between two basic types of experience as conceptually interpreted - and perhaps difference on the experiential level of the degree to which a sense of self abides or departs-hardly denies the possibility of similarities or common core(s) to mystical experiences. 
We have seen the irony of the constructivist premise of no noumena or proto-object to interpret-or at least nothing that constrains interpretation. In a further irony, the constructivists end up with a position regarding the issue of mediation similar to those who tout undifferentiated identity, for both maintain the strictly content-less nature of whatever, if anything, the mystic experiences prior to interpretation. Of course, these latter essentialists hold that pure, content-less, unmediated experiences occur apart from interpretation afterwards. But for the former, experiences lack content save for the mystic's conceptual constructs; from an opposite direction mediation is absent, for again nothing exists-no object- to mediate, or at most an utterly inchoate and content-less emotive-physiological state.

Speaking of mediation, the contemporary consensus accepts the mediated nature of ordinary consciousness and experience. Before proceeding further in the tasks of tackling critically and constructively mystical experience and mediation, I will introduce my perspective of "radical embodiment," wherein everyday consciousness is radically mediated by the body, indeed rooted in the body, substantively as well as instrumentally. Elsewhere, I argue that even our linguistic experience always builds and relies upon our sensorimotor orientation to and action in the world (Nikkel, 2006a). Human consciousness is embodied consciousness that evolved biologically for the sake of the organism. Neuroscientists Antonio Damasio and Gerald Edelman theorize that consciousness arises through brain mappings of one's body in correlation to the environment. As suggested earlier, while mappings in the posterior parietal lobes appear to play an especially significant role in spatial orientation, many parts of the brain figure in our sense of self. Indeed, for Damasio and Edelman, every perceptual sense involves mappings of our bodies in relation to the environment. Both scientists conclude that all mammals have a "basic" or "proto" consciousness that distinguishes self from others and the environment. Only humans have a higher consciousness that entails the ability through language to objectify and reflect upon our sense of self. Damasio in particular focuses on emotions or feelings as integral to the sense of self. Emotions are first of all about the body and its state-though usually involving some direct or indirect relationship to the social or natural environment. I find especially helpful Damasio's notion of "background body feelings": in addition to stronger feelings of, say, sadness or joy, we do have feelings about the state of various parts of our body, not only on the surface or near surface areas but also with respect to our viscera. It is no coincidence for Damasio that "how do you feel?” is a common question of greeting. For persons with an integral sense of bodily consciousness, we immediately become aware of a pain say in our big toe because of this constant monitory awareness. These background body feelings, normally peripheral to our focal consciousness, still inescapably color all our ordinary conscious experience. The embodied reality, for example, of a mouse or a dolphin means that the color or tone of its experience will differ somewhat from ours.

Now we are ready to proceed further in considering mediation and mystical experience. I will examine in turn three types of experiences: (1) the most radical: an experience of the divine, circumscribed both as to the number of participants and in time, where all sense of ordinary subject-object consciousness drops away; (2) the Tillichian model with its ubiquitous immediate experience of the divine beyond subject-object, albeit usually in the background, always accompanied by some subject-object consciousness; (3) the Jamesian model where some distinction between human subject and divine object remains at every point.

I can think of two models for the first type, radical and exclusionary in the sense that subjectobject consciousness completely rescinds. Of course, any serious scholar within the academy or a major world religion acknowledges that normal consciousness always correlates with neural activity. Nevertheless, at least a few dualists regard this correlation as metaphysically incidental and inessential (for example, Eccles). This position is compatible with the further theory that when the subject-object component of consciousness, correlated with brain activity, fades away, 
pure consciousness, divine consciousness, the deeper essence of consciousness unmediated by any neural activity, remains. Whether or not anyone today explicitly advocates this theory, it does accord with some traditional mystical philosophy in at least Advaita Hinduism and Theravada and Mind-Only Buddhism.

A more plausible model, however, holds that the brain does mediate an experience of identity with the divine completely transcending subject-object consciousness. This model, in keeping with the results of neuroscientific research, grants that various parts of the brain involved in ordinary consciousness differentiate or become quiescent. Note what this model entails: those mediating parts of the brain are utterly transparent to this pure divine consciousness. Though normally involved in subject-object consciousness, they do not color or filter this experience. Background body feelings, referred to earlier, in no way impinge on this state of consciousness. That one may achieve absolute knowledge unmediated by human language, culture, tradition, and bodies I regard as an Enlightenment conceit. Or more precisely, the conceit assumes that such human mediators have no effect on our knowledge-it assumes their absolute transparency to their object. (Unwittingly some radical postmodernists or poststructuralists end up replicating the error of the incidental nature of these human mediators through an unbridled constructivism, though now there is no concrete object to reach [Nikkel, forthcoming].)

To say more about inductive evidence that mediation affects all human knowledge is beyond the scope of this article. I concede the theoretical or logical possibility of the complete transparency of some human brains to a divine consciousness beyond subject-object. But I would note that the supporters of this model carve out an exception to the way the brain otherwise functions in knowing - albeit this alleged pure consciousness is an exceptional state. One does not need to be convinced as I am that mediation makes a difference in all knowledge to judge this model negatively. Those taking embodiment or evolutionary biology/ neuroscience seriously will likely find it implausible as well. For if our brains evolved in conjunction with our bodies as biological organisms, the evolution of brain structures able to function as a transparent conduit to a divine consciousness seems improbable.

I will now consider the second scenario where an experience of undifferentiated unity with the divine constitutes only part of one's total experience or awareness. As one reader of the proposal for a version of this essay put it, one may have a mystical experience even as "the bodily feelings... just inevitably come along for the ride." Indeed, Tillich's "mediated, unmediated" experience of the ultimate falls precisely under this hybrid category: humans have an awareness of ultimacy beyond the subject-object cleavage that never constitutes their total awareness at any moment. Tillich's mystical a priori always combines with an a posteriori, in a kind of synthesis reminiscent of Kantian epistemology. The pure experience of the divine makes up part of an "impure" total experience. Before directly addressing the problem of mediation, I will note a radical aspect of Tillich's model. Unlike the first model, everybody has a mystical awareness as a component of every experience-or at least every human of a certain age with normal capabilities. But why stop there? Might not any animal with some awareness or consciousness have such an experience? As the prius of all subject-object relations, logical consistency would seem to demand that, if one type of sentient creature experiences the divine, all do. Obviously a mouse or lizard could not conceptualize or interpret its experience of the mystical a priori. This fact points to an interesting issue: while Tillich characterizes the identity beyond subject-object as contentless, this awareness is associated with a sense of the unconditional nature of this divine reality. This awareness has clear parallels, in a Romantic intuitionist vein, to Schleiermacher's "feeling of absolute dependence." While this kind of awareness strikes one as more general than particular or specific, one could well regard it as a type of content rather than strictly content-less. The question arises: Does a feeling of unconditionedness or of absolute dependence occur as part and parcel of the experience, or is it an interpretation or (at least proto-) conceptualization, albeit 
intuitive? Since for Tillich the mystical a priori comes with every human experience even though we might fail to consciously recognize it-and by extension probably with every creaturely experience, I conclude that this sense of unconditionedness involves some interpretation.

Admittedly the above has been something of an excursion. But I will now cut to the chase. What, if anything, mediates this universal awareness of the divine? We could hypothesize that the mystical a priori simply bypasses our brains, as we first did with the exclusionary or unmixed experience of identity beyond subject-object. However, for Tillichian thought, a theologically fatal objection arises: This alternative more than smacks of the "supranaturalism" anathema to Tillich. (Though at least in this case of a universal mystical a priori sans bodily mediation, the supranaturalism would be built into the structure or "pre-structure" of the universe rather than constitute an occasional intervention.)

The second possibility, again paralleling our consideration of the unmixed experience, is that our brains mediate the mystical a priori-human brains and mouse brains —although, in the latter case no conceptualization could ensue. Yet to uphold the crucial element of transcendence of the subject-object structure, this mediation must be completely transparent, as with the exclusionary model. We must imagine then that the brains of all sentient creatures evolved so as to allow this transparency. While theoretically possible, this seems much more implausible than the notion that only human brains happened to so evolve.

The reader for whom my above arguments and assumptions resonate will grant the improbability of mystical experience with no mediation or transparent mediation, where all sense of subject and object vanishes. Yet what of those mystical experiences, perhaps involving some images and/or some emotions, perhaps involving a profound sense of divine love, where some distinction between subject and object remains, even though much of the usual sense of separation has evaporated? William James postulates a mystical experience involving our perception of supernatural mind(s). His use of "perception" is significant for it entails some retention of a subject-object structure. Still this perception is rather direct. Our subjectivity remains and our brains still operate, though in an unaccustomed way, but the fence at the margins of our consciousness comes down, allowing us to experience the consciousness of another, which is normally subliminal to us. This supernatural consciousness of which we become aware does itself lie within the subject-object realm and thus has contents. However, our awareness of it lacks specific knowledge of the contents. It is somewhat analogous to the memory we sometimes have of a dream where all the details have vanished. (Interestingly, James regarded several of his dreams as such an awareness of supernatural consciousness.) Having outlined James's postulation of direct human perception of a supernatural mind when the fence confining our ordinary consciousness comes down, I now raise the critical question of whether this model squares with his understanding of consciousness as a psychological and biological process. James himself would see this as a legitimate question, as he regards all experiences as instantiations of these processes.

James's delineation of consciousness as a flowing activity is still standard in the field of psychology. He noted both consciousness's orientation to the general environment or "streaming array" as well as its recognition of particulars that satisfy biological needs or drives. James's most basic theory of consciousness, therefore, acknowledges its entailment of a subject aware of its environment and of objects, some of the latter of which may be subjects in their own right. Since James does not endorse undifferentiated unity, we have a preliminary consistency with respect to his model of mystical experience. While James obviously did not possess today's knowledge of evolutionary development and neuroscience, he did uphold the evolutionary adaptiveness of consciousness along with its biological nature. So how might subliminal awareness of other consciousnesses that occasionally becomes direct fit into James's scheme? James of course just dealt with human awareness of other consciousnesses, but I see no reason why it should not apply 
to other animals given his assumptions. If awareness of other consciousnesses were both specific and under the organism's control, the survival advantage for some creatures is apparent: for example, a mouse would find it most helpful to know of Tabby's intention to pounce. Unfortunately, as we have seen, such awareness normally lacks specificity. (Exceptions for James include automatic writing and mediumship where deceased human spirits might transmit a particular message.) Also unfortunately, the subliminal does not come into direct awareness whenever it would benefit the organism.

In addition, as with Tillich's mystical a priori, awareness of a supernatural consciousness would not prove beneficial to a non-human animal unable to interpret or conceptualize it. Furthermore, according to James these experiences sometimes prove negative due to the psychological make-up of the experient and/or possibly due to the evil intentions of a supernatural consciousness.

Thus, our discussion of the biological adaptiveness of mystical and related extraordinary experiences on James's model ends in ambiguity. More daunting, however, as with experiences of undifferentiated identity, is the question of mechanism. What perceptual sense or combination of senses-or any aspect of the body and the brain, however intuitive-inputs these other consciousnesses? To my knowledge James did not address this issue. Neo-pragmatist William Dean, however, has. Given that the five senses are "in abeyance" (James, 1902:424), Dean characterizes this direct perception as a bodily "non-sensuous perception." Further, he claims that in general "what the body receives is mostly non-conscious, indefinite, and neither transmittable to nor translatable by the senses or cognition" (8). I agree with the non-conscious nature of most of what our bodies input and would add that the bulk of what contributes to our explicit knowledge is subconscious, tacit, and indefinite-explicit cognition forming the tip of the iceberg. The controversial- indeed if my intuition is correct-dubious, part concerns the assertion that we receive input from outside our bodies not transmitted through our five senses that contributes to cognition - in this case cognition of a divine consciousness. Granted the jury is still out on at least one type of extraordinary sense perception, namely, whether people can detect at a rate greater than chance when they are being observed by another without any direct perceptual signals. That leaves us, however, with a dearth of empirical evidence of extraordinary cognition of the consciousness of another.

Moreover, the lack of any candidates from contemporary scientific knowledge for the mediation of such experiences of the contents of other consciousnesses definitely counts against the plausibility of James's model — and probably against other models—of mystical experience where some distinction between human subject and divine object remains. On the face of it, this rather direct transmission of the mental contents of one being to another appears more immaterial or idealistic than bodily. Finally, one could resort to a supernaturalism tailored to mystical experience where some subject-object distinction abides: God miraculously works on the brains of mystics to induce whatever experiences God desires, but leaves no physical evidence of this divine action in the external environment. This would contradict Jamesian metaphysics, however, where even "supernatural" forces act within the laws and processes of the universe in the broadest sense.

James appended to his basic psychological model of consciousness a theory of perception as "pure experience" of a datum combining subject and object, which we then sharpen into a clear subject-object distinction. This theory does not insist on a complete absence of distinction between subject and object in the earliest moments of perception. However, it does uphold a much greater unity of subject and object than we find in finished perception and experience. The sharing of the phrase "pure experience" with many mystics and scholarly proponents of undifferentiated unity is suggestive. If true, this theory of perception would increase the plausibility of direct experience of the supernatural. Unfortunately the whole thrust of 
evolutionary biology in general, of the neurobiological theories of Damasio and Edelman in particular, and of neuroscientific evidence thus far indicate that consciousness evolved through the plotting of changes in the (relatively homeostatic) body with respect to changes in the environment. As suggested earlier, our brains- map what occurs in our bodies, what occurs in our environment, and the correlations between the two. This is to say that a subject-object distinction enters on the ground floor of conscious perception (indeed built upon preconscious processes of correlative representations of environment and organism).

Before advancing to my own constructive work on the nature of mystical experience, I want to address a common argument for the reality of mystical experiences of either the undifferentiated or differentiated kind: the sense of the reality of the object or of that which transcends subject-object by many mystical experients. Newberg, though not a philosopher or theologian, addresses this issue from a so-called "neuroepistemological" perspective. He cites three criteria by which the brain might judge an experience as real: "the subjective vivid sense of reality," "duration through time," and "agreement intersubjectively as to what is real," but concludes that the latter two collapse into the first (2006). I judge that he dismisses duration and inter-subjective agreement much too quickly. He gainsays the former by noting that the brain structures one's sense of time, with certain brain injuries distorting one's perception of time while some mystics experience no sense of time or duration at all. Yet we do have more, objective scientific evidence that time in any given spatiotemporal frame of reference passes at the same rate whatever our subjective experiences. On the latter, while undoubtedly some more or less instant neurological criteria exist that enable us to consider some experiences and not others as candidates for "reality," inter-subjective agreement constitutes a powerful tool to judge the reality of experiences called into question. Thus I conclude that a subjective sense of reality does not succeed as a strong argument for the reality of their object/“non-object.”

From the above, I obviously part company with both camps of essentialists. Yet, as suggested earlier, both reports of mystical experiences and scientific research point to some experiential and physiological-neurological common core to most mystical experiences, both more emotiveimagist and "purer" ones. I propose that the mystical object is not an "external" supernatural one, but more internal to our embodied consciousness. But what mediates what in mystical experience? Larry Short makes a good start in theorizing that the mediation in mystical experience is non-linguistic (though of course describing the experience afterwards entails linguistic mediation) (664ff). Barnard also admits the reality of "pre-linguistic" or "translinguistic" experience. Larry Short suggests that any experience involving "an interruption in the movement from signifier to signified," where we "get hung up in between"-in other words involving consciousness but not of any particular object, and which takes on religious meaning is mystical (668ff). This strikes me, though, as insufficiently specific. Brief, indeed momentary, everyday experiences where one loses awareness of object or signified would not usually, if ever, incorporate a diminished sense of self let alone unity with some larger reality. Mystical experiences by contrast, usually cultivated and relatively sustained, do entail a change in sense of self. Some have hypothesized that all religious experiences involve cross-modal translations of various perceptual senses, thus promoting a unitive feeling (e.g., Winkelman). However, in many mystical experiences the senses do seem to be in abeyance. Amy Hollywood in her recent book, Sensible Ecstasy, highlights the frequent employment of erotic images and language in the descriptions of medieval mystics and recommends the cultivation of diverse forms of sensual experience. Previously Jeffrey Kripal authored Roads of Excess, Palaces of Wisdom: Eroticism and Reflexivity in the Study of Mysticism. In that work he notes that erotic love in general diminishes the sense of a separate self as it increases the sense of unity with another (12). However, I would note crucial dissimilarities of ordinary erotic experiences from mystical ones: in human sexual experiences pronounced physiological changes occur in certain parts of the body 
and the brain, while the one with whom one unites is a particular finite individual. With respect to the brain, Newberg notes similarities between orgasmic and unitive states, but also significant differences: the hypothalamus appears to play a more prominent role in sexual climax, while cortical frontal lobes take a more active role in mystical states (Horgan). In Sacred Pain: Hurting the Body for the Sake of the Soul, Ariel Glucklich considers the role of pain in stimulating certain religious experiences. Glucklich argues that pain can break down the sense of self, thus opening one up to a sense of unity with the sacred (e.g., 207). Without disagreeing with that assessment, I would observe that pain bears no necessary or unique relationship to mystical experience. On the one hand, overwhelming pain sometimes simply dissolves the sense of an integrated self, leaving one incapable of reintegration with a larger reality or meaning. On the other hand, most mystical experiences have not involved pain as a method to achieve greater unity.

The above theories on mystical experience have the advantage of highlighting our embodied nature. Except for Short's account, they rightly highlight a lessened sense of a distinctive self to the benefit of a greater sense of unity with the other as crucial to mystical experience. I will advance an embodied version of mystical experiences wider in some ways than any of those accounts, yet still circumscribed: its object is not as definite as in cross-modal or erotic experiences, nor is pain a necessary preliminary object, yet its content differs in kind from any mundane experience where one momentarily loses awareness of any particular object. Mystical experiences consist of a distinctive sense of bodily harmony conjoined with a general openness to the potentialities of an integrated environment-thus their expansive and unitive quality. A lessening of the sense of one's self as simply separate and distinct from others and a concomitant upsurge in the sense that one forms part of a larger reality along with other particular realities constitute a key part of the distinctive quality of this type of experience or state. This state involves distinctive neurological processes, referred to earlier, about which our scientific knowledge continues to grow. Such experiences may be, and historically sometimes-indeed often-have been, interpreted as escape from our world to an otherworldly reality. But a better interpretation is available: the special sense of openness to unity with an other typical of mystical experiences conduces to a deep sense of harmony and empathy with our fellow human beings, other living creatures, as well as with the supernatural ultimate of the world's religions.

Before concluding, let me review and summarize the reasons and arguments I cited against the essentialist positions: Human (and other animals') bodies and brains evolved in order that biological organisms might flourish in natural (and social) environments. This entailed some distinction between subject and object on the ground floor of sentience or consciousness. While one cannot rule out a priori the possibility of human or other animal brain structures evolving with a transparency to the divine consciousness, this is unlikely given the more "translucent" mediation of object by subject that pervades conscious life. Regarding essentialists who maintain some distinction between mystic and the divine, implausibility lies in the empirical lack both of identifiable brain structures or mechanisms to tap into the divine consciousness and of evidence that organisms gain awareness of the consciousness of other organisms apart from perceptions and reflection upon these. What of the mystic advocating unmediated identity who claims that the reduced sense of distinction of self from other that I posit in mystical experiences can reach the point where sense of self somehow disappears and even that what remains is precisely divine consciousnesss? I would first refer back to the general non-reliability of subjective certainty in such matters. More particularly, I would suggest that the mystic is probably misreading her or his experience, given what we know about the nature of human and animal consciousness.

Undoubtedly for some, my denial of unmediated or direct connection with the divine concedes game, set, and match to the constructivists. Yet given other reasons discernible from our bodily being in the world that validate the truth of the purposive interconnection of all life within the span of such an ultimate reality, why should we not value mystical experiences so interpreted? 
After all, epistemologically speaking, James and Tillich both hold that mystical experiences never yield specific information about the divine: Tillich because of his espousal of the universal mystical a priori and James because we finally cognize only a holistic sense of the co-conscious enveloping supernatural rather than any particulars. And, of course, James's pragmatic concern with moral fruitfulness invites us to value mystical experiences whatever their ultimate cognitive status. We no longer live in or under the influence of a Romantic age that assumed a direct connection with the divine at the level of intuition or feeling. But the varieties of mystical experience that captivated William James and Paul Tillich may stimulate us to imagine more bodily connections with the divine for a postmodern age.

\section{References}

Adam, Martin T. (2002) “A Post-Kantian Perspective on Recent Debates about Mystical Experience.” Journal of the American Academy of Religion 70, 4: 801-41.

Barnard, G. William (1992) "Explaining the Unexplainable: Wayne Proudfoot's Religious Experience.” Journal of the American Academy of Religion 60, 2: 231-56.

Brainard, F. Samuel (1996) "Defining 'Mystical Experience'.” Journal of the American Academy of Religion 64, 2: 359-93.

Damasio, Antonio (1994) Descartes' Error: Emotion, Reason, and the Human Brain. New York: G. P. Putnam's Sons.

d'Aquili, Eugene, (1999) The Mystical Mind: Probing the Biology of Religious Andrew B. Newberg Experience. Minneapolis: Fortress Press.

Dean, William (2003) “A Neglected Apology for Mystery.” Paper presented to the American Academy of Religion Annual Meeting, Atlanta, Georgia.

Eccles, John (1989) Evolution of the Brain: Creation of the Self. New York: Routledge.

Edelman, Gerald (1992) Bright Air, Brilliant Fire: On the Matter of the Mind. New York: Harper Collins.

Forman, Robert K. C. (1993) “Mystical Knowledge: Knowledge by Identity.” Journal of the American Academy of Religion 61/4:705-38.

Glucklich, Ariel (2001) Sacred Pain: Hurting the Body for the Sake of the Soul. New York: Oxford University Press.

Hamer, Dean (2004) The God Gene: How Faith Is Hardwired into Our Genes. New York: Doubleday.

Hollywood, Amy (2002) Sensible Ecstasy: Mysticism, Sexual Difference, and the Demands of History. Chicago: University of Chicago Press.

Horgan, John (2006) “The God Experiments.” Discover 27/12.

Idel, Moshe (1989) Mystical Union and Monotheistic Faith: An Ecumenical Bernard McGinn Dialogue. Editors and contributors. New York: Macmillan.

Izutsu, Toshihiko (1983) Sufism and Taoism: A Comparative Study of Key Philosophical Concepts. Berkeley: University of California Press.

James, William (1902) The Varieties of Religious Experience. New York: Longmans, Green.

James, William (1890). The Principles of Psychology. 2 vols. New York: Dover.

Katz, Steven T. (1978) Mysticism and Philosophical Analysis. Editor and contributor. New York: Oxford University Press.

Kripal, Jeffrey (2001) Roads of Excess, Palaces of Wisdom: Eroticism and Reflexivity in the Study of Mysticism. Chicago: University of Chicago Press.

Monasterksy, Richard (2006). “What Happens to Your Brain while Praying?” Chronicle of Higher Education, May 26: A17.

Newberg, Andrew (2005). "Field Analysis of the Neuroscientific Study of Religious and Spiritual Phenomena.” Metanexus Digest 5, 4. 
Newberg, Andrew (2001). "Brain Science and the Biology of Belief, Part 2.” Metanexus Monthly, Vol.1, "Views."

Nikkel, David (Forthcoming). Radical Embodiment, Eugene, Oregon: Wipf \& Stock.

Nikkel, David (2006a). "Humanity and Divinity as Radically Embodied.” Metanexus Digest 6, 11.

Nikkel, David (2006b). “The Mystical Formation of Paul Tillich.” Bulletin of the North American Paul Tillich Society 32, 2:15-21.

Penner, Hans H. (1989). “The Encyclopedia of Religion.” Critical Review of Books in Religion, 1-21. Atlanta: Scholars Press.

Proudfoot, Wayne (1985). Religious Experience. Berkeley: University of California Press.

Sells, Michael (1994) Mystical Languages of Unsaying. Chicago: University of Chicago Press.

Shear, Jonathan (1994). "On Mystical Experiences as Support for the Perennial Philosophy." Journal of the American Academy of Religion 62/2: 319-42.

Short, Larry (1995). "Mysticism, Mediation, and the Non-Linguistic.” Journal of the American Academy of Religion 63/4: 659-75.

Simoni-Wastila, Henry. (2000). "Unio Mystica and Particularity: Can Individuals Merge with the One.” Journal of the American Academy of Religion 68/4: 857-78.

Stace, W. T. (1960) Mysticism and Philosophy. London: Macmillan.

Tillich, Paul (1959). Theology of Culture. Ed. by Robert C. Kimball. New York: Oxford University Press.

Winkelman, Michael (2004) "Shamanism as the Original Neurotheology.” Zygon: Journal of Religion and Science 39/1:193-217. 